has been the voice of forest practitioners since 1908. Members include foresters, forest technologists, forest technicians, educators, scientists and others with a professional interest in forestry.

Mr. Moores graduated from the University of New Brunswick in 1981 with a Bachelor of Science in Forestry degree. In May, 2001 received his Master of Forestry degree from Lakehead University. Has been employed with the Department of Forest Resources and Agrifoods' Newfoundland Forest Service for 21 years in a variety of positions, including silviculture, management planning, environment and land use planning and environmental assessment. Mr. Moores has also published papers on site classification, forest management planning, and forest policy.

Mr. Moores is the chair of the Advisory Committee for the Forest Technician Program at the Corner Brook campus of the College of the North Atlantic, co-coordinator and a coach for the Special Olympic program in Corner Brook, treasurer for the Corner Brook branch of the Autism Society of Newfoundland and Labrador, and a scout leader for 20 years.

Media contacts: Len Moores, Director
of Ecosystem Health, (709) 637- 2297
Sonia B. Glover, Communications, (709) 729-6183

\title{
Information Technology / Technologie de l'information
}

\section{Information Technology and the Forest Sector - IUFRO Task Force}

\section{Background}

The emergence of new information technology (IT) creates new challenges and opportunities for the global forest sector. For example, digital IT can be a substitute for newsprint, letter paper, paper used for archiving, etc. On the other hand, the development of IT can increase the demand for new paper types suitable for high-quality digital color printing. IT may not only lead to drastic changes in the demand pattern but also to increased usage of IT in the forest industry, which can enhance production efficiency and reduce costs. In particular, IT may be helpful in the business-to-business, logistic, and marketing stages. For example, online market places for raw materials and paper products are likely to play increasing roles in the future. Therefore, IT will also help to increase and maintain the competitiveness of paper products in the future.

\section{Objectives}

The objectives of the new IUFRO Task Force on "Information Technology and the Forest Sector" are:

- to establish an operational network to identify and co-ordinate research and activities on the topic of the task force,

- to produce a task force report.

The operational network to be established will implement the research program needed, organize data sharing, carry out methodological development and analysis, disseminate the Task Force findings and results of the network activities. The Task Force Report will describe state of the art knowledge and assess the future research needs on the topic.

\section{Execution of the Task Force}

The Secretariat for the Task Force is located at the Forestry Project of the International Institute for Applied Systems Analysis (IIASA), Laxenburg, Austria. IIASA and the Finnish Forest Institute (METLA) are the founding institutions of the Task Force, and the Task Force will harvest from already ongoing activities in this field at these two institutions. Members of the Task Force and the operational network will be recruited among IUFRO member scientists and other experts in the field. The IUFRO Secretariat in Vienna will support the operational network. Required Task Force meetings will be organized by and take place at IIASA. A substantial part of the work will be handed through the Internet and specially designed Web pages. the costs for participation in the Task Force will be covered by the participants' home organizations.

\section{Time Horizon}

The Task Force started its work in early 2002 and will present the final Task Force report at the IUFRO World Congress in Brisbane, Australia in 2005. The operational network will continue to conduct work after 2005.

\section{Network}

Currently, the following scientists have signed up as partners in the Task Force network:

Darius Adams, OSU, USA

Torjus Bolkesjø, AUN, Norway

Gary Bull, UBC, Canada

Lauri Hetemaki, METLA, Finland

Ian McCallum, IIASA, Austria

Sten Nilsson, IIASA, Austria

Michael Obersteiner, IIASA, Austria

Olman Serrano, FAO, Italy

\section{IUFRO Division Contacts}

Div. 1 - John Parrotta, USDA, USA

Div. 2 - TBA

Div.3 - Hideo Sakai, UoT, Japan

Div.4 - Alan Thompson, CFS, Canada

Div.5 - Richard P. Vlosky, LSU, USA

Div.6 - Carol Green, UoW, USA

Div. 7 - Katsumi Togashi, HU, Japan

Div.8 - TBA

Primary contact for general questions and inquiries: Prof. Sten Nilsson, International Institute for Applied Systems Analysis, A-2361 Laxenburg, Austria, e-mail: nilsson@iiasa.ac.at

Phone: +43 2236 807-229

Fax: +43 2236 807-599. 
Definitive on-line forestry information resource launched by CABI Publishing

\section{ForestScience.info - new website}

CABI Publishing, producer of Forestry Abstracts, TREECD* and the Forestry Compendium has launched a new Website - ForestScience.info. ForestScience. info contains comprehensive coverage of the world's scientific literature in forestry and related disciplines dating back to 1939.

Research database - For 65 years, CABI has synthesized the vast amount primary research literature available from around the world to provide researchers, scientists and forestry decision-makers with access to one comprehensive forestry database. The ForestScience.info database now contains over 600000 research summaries, with over 20000 new research summaries added each year.

The Latest research - ForestScience.info includes the latest research summaries, enabling forestry professionals to keep upto-date with current research. An e-mail alert service is available for those who want weekly updates of new abstracts in their areas of interest sent directly to their email inbox.

Full-text linking - ForestScience.info offers both subscription-based access to full-text articles and the option of singlearticle purchase.

ForestScience.info also contains links to CABI's forestry bookshop for reading and purchase, and access to the Resource Discovery Network enabling users to search important Internet resources in their subject area.

ForestScience.info is a subscriptionbased site, with competitive rates based on the size of the institution. Full details and a free trial are available at www.ForestScience.info

To review ForestScience.info, simply e-mail t.canning@cabi.org for temporary free access.

For more information please contact: Theresa Canning, CABI Publishing Tel: 01491829196 e-mail: t.canning@cabi.org

\section{Forest Fire Sensing Prototype}

The 2002 wildfire season has been one of the worst in modern history. But what if we could sprinkle an entire forest with computer sensors that could detect heat from fire and alert officials before a blaze gets out of control? It would be like putting smoke detectors on trees and a prototype developed by Accenture Technology Labs shows that it's possible.

The forest fire sensing prototype uses small robotic sensors hung on trees that can actively sense, record and transmit information about the surrounding environment. When a sensor detects heat from fire it sends a warning message to fire officials who have a view of their forest on a computer screen. This gives firefighters a chance to be alerted to a fire before it spreads exponentially. Accenture believes in the nottoo-distant future, these computer sensors will become dust size and could be sprinkled on anything that could cause concern, like a bridge or a pipeline.

Contact: Alison Geib On Behalf of Accenture 310-318-8879

\section{New Web Site on Defoliating Insects of Conifers in BC}

The spruce budworm, blackheaded budworm and hemlock looper are all well-known forest defoliators that frequently cause extensive damage to Canada's forests. But there are also less-common defoliator species, which, although usually innocuous and sometimes rare, are important elements of forest biodiversity. Until now tools that would enable forest stakeholders to accurately identify this important group of insects have not been available. Yet such tools are essential if field foresters, biologists, researchers, naturalists, environmentalists and educators are to appropriately manage damaging species and develop a greater understanding of the roles defoliators play in the forest ecosystem.

The Canadian Forest Service, Pacific Forestry Centre has recently launched a new Web site, Conifer Defoliating Insects of British Columbia (http://www. pfc.cfs.nrcan.gc.ca/entomology/defoliators). The Web site describes both damaging and non-damaging insects that feed on the foliage of any of the 24 species of conifers native to the province.
The site currently includes about 30 percent of the 140 defoliators species known to feed on conifers in BC.

"The 40 species currently posted on this web site represent the first segment of an upcoming comprehensive guide that will ultimately include all conifer defoliators known to occur in BC," says Bob Duncan (available at rduncan@pfc.cfs. nrcan.gc.ca), an insectary biologist at the Pacific Forestry Centre. Since 1972, Duncan has been providing insect diagnostic services for the Canadian Forest Service. Thirty years of working with forest stakeholders in government, industry, the scientific community and the general public uniquely qualifies Duncan to produce this guide.

"All insect species play an important role in the ecological relationships of the forest," says Duncan. "Insect defoliators - primarily caterpillars and sawfly larvae - are important elements of forest health and biodiversity. Some species periodically go into outbreak causing considerable economic loss to the forest resource while other species are rare and may require conservation efforts."

Duncan explains that identifying the immature stages of many species can be difficult because few larval keys exist and those that do only cover a few of the defoliating species occurring in BC. Also, these keys are widely dispersed in the taxonomic literature and are not illustrated with colour photos. The new Web site Conifer Defoliating Insects of British Columbia, however, includes larval descriptions, life history data and colour photographs for each species.

The Web site lists defoliators not only by common and scientific name, but also by family and host tree. Defoliating insects occurring on the following hosts are described on the Web site: western redcedar, yellow-cedar, Douglas-fir, amabilis fir, grand fir, subalpine fir, mountain hemlock, western hemlock, common juniper, Rocky Mountain juniper, subalpine larch, tamarack, western larch, jack pine, limber pine, lodgepole pine, ponderosa pine, western white pine, whitebark pine, black spruce, Engelmann spruce, Stika spruce, white spruce and western yew.

The Web site will be updated annually until all species are included. The hardcopy version of the guide, describing all conifer defoliators in $\mathrm{BC}$ is expected to be available in early 2005 .

Source: Information Forestry 